\title{
Influência das matrizes econômicas e sua relação com o clima: município de Porto Velho/RO
}

O modelo de ocupação populacional e crescimento econômico de Porto Velho/RO foi baseado em incentivos do governo federal através de programas de assentamento. Em 2008, Porto Velho, mais uma vez, foi inserido em programas federais de crescimento econômico, desta vez no Programa de Aceleração do Crescimento (PAC). Tal modelo de desenvolvimento desencadeou mudanças significativas na dinâmica do uso da terra e nos recursos naturais dessa região. Além desses impactos está a emissão de $\mathrm{CO} 2$ através das atividades de desmatamento, recuperação de terras, criação de gado e incêndios florestais. Sabendo que o CO2 é um dos principais responsáveis pelo aumento da temperatura do planeta, Porto Velho e região tornam-se potentes contribuintes para o fenômeno das mudanças climáticas. O objetivo deste estudo foi verificar o cenário atual de Porto Velho, do ponto de vista ambiental, econômico, social e climático, com base na análise de indicadores entre 1990 e 2015. A definição de indicadores deu-se a partir da pressão - Estado - Metodologia de resposta (PER). Concluiu-se ao final do estudo, que houve mudança nas variáveis climáticas: temperatura, umidade relativa e precipitação. As análises estatísticas também mostraram fortes associações entre os indicadores de uso da terra e crescimento econômico com o indicador de $\mathrm{CO} 2$, e, no entanto, essas mesmas análises não mostraram melhorias significativas na qualidade de vida da população de Porto Velho.

\section{Influence of economic matrix and its relation to the climate: municipality of Porto Velho/RO}

\begin{abstract}
The model of population occupation and economic growth of Porto Velho/RO was based on incentives from the federal government through settlement programs. In 2008, Porto Velho was once again included in federal economic growth programs, this time in the Growth Acceleration Program (PAC). Such a development model triggered significant changes in land use dynamics and natural resources in this region. In addition to these impacts is the emission of CO2 through deforestation, land reclamation, cattle raising and forest fires activities. Knowing that $\mathrm{CO} 2$ is one of the main responsible for the increase of the planet's temperature, Porto Velho and region become potent contributors to the phenomenon of climate change. The objective of this study was to verify the current scenario of Porto Velho, from the environmental, economic, social and climatic point of view, based on the analysis of indicators between 1990 and 2015 . The definition of indicators was based on the pressure - State - Response Methodology (PER). It was concluded at the end of the study that there was a change in climate variables: temperature, relative humidity and precipitation. Statistical analyzes also showed strong associations between land use and economic growth indicators with the $\mathrm{CO} 2$ indicator, however, these same analyzes did not show significant improvements in the quality of life of the Porto Velho population.
\end{abstract}

Keywords: Climate Change; CO2 Emission; Land Use Change.

Topic: Meteorologia, Climatologia e Mudanças Climáticas

Reviewed anonymously in the process of blind peer
Received: $12 / 04 / 2019$

Approved: 27/05/2019
Karem Franciely Dutra (iD)

Universidade Estadual do Mato Grosso, Brasi

http://lattes.cnpq.br/3695707144179021

http://orcid.org/0000-0002-4726-0219

karemfranciely@hotmail.com

\section{Wilkinson Lopes Lázaro}

Universidade Estadual do Mato Grosso, Brasi

http://lattes.cnpq.br/0263718697915954

http://orcid.org/0000-0002-6499-6631

wilkinsonlopes@gmail.com

Sandra de Souza Hacon (iD)

Universidade Federal Fluminense, Brasil

http://lattes.cnpq.br/7653379361147439

http://orcid.org/0000-0002-8222-0992

sandrahacon@gmail.com

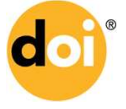

DOI: 10.6008/CBPC2179-6858.2019.003.0006
Referencing this:

DUTRA, K. F.; LÁZARO, W. L.; HACON, S. S.. Influência das matrizes econômicas e sua relação com o clima: município de Porto Velho/RO. Revista Ibero Americana de Ciências Ambientais, v.10, n.3, p.52-62 2019. DOI: http://doi.org/10.6008/CBPC2179-6858.2019.003.0006 


\section{INTRODUÇÃO}

Seja por interferência humana ou de forma natural, a preocupação com o fenômeno mudança climática tem se intensificado no meio científico, político e movimentos ambientalistas desde a década de 1970. Segundo estudos científicos, o aumento das concentrações dos Gases de Efeito Estufa - GEE $\left(\mathrm{CO}_{2}, \mathrm{CH}_{4}\right.$, $\mathrm{N}_{2} \mathrm{O}$ e CFC's) no sistema climático são os principais indutores à mudança do clima (IPCC, 2007; SOARES, 2014; PIFER et al., 2015).As emissões de GEE são estimadas em $\mathrm{CO}_{2}$ equivalente (CO2e), obtido por meio da multiplicação do $\mathrm{CO}_{2}$ pelo seu Potencial de Aquecimento Global (IPCC, 2007). Partindo da premissa de que este é um tema que deve ser abordado em escala global, a Organização Meteorológica Mundial - OMM e o Programa das Nações Unidas de Meio Ambiente - PNUMA estabeleceram em 1988 o Painel Intergovernamental de Mudanças Climáticas - IPCC.

O solo e a vegetação são componentes determinantes para o fenômeno de mudanças climáticas devido ao seu potencial de retenção de $\mathrm{CO}_{2}$ e $\mathrm{CH}_{4}$. O carbono é acumulado no solo por meio da matéria orgânica, por isso atividades como reflorestamento, plantio direto e pastagens que não geram o revolvimento do solo promovem maior retenção de $\mathrm{CO}_{2}$ quando comparado às atividades agrícolas que utilizam técnicas de revolvimento do solo (CARVALHO et al., 2010; CERRI et al., 2009). Entretanto, manejos inadequados podem transferir grandes quantidades de $\mathrm{CO}_{2}$ para a atmosfera (CERRI et al., 2007).

O desenvolvimento econômico da região Amazônica está associado principalmente ao agronegócio, atividade que fomentou intensa degradação das áreas de floresta que foram convertidas em áreas de pastagens ou áreas de monocultura agrícolas. Os estados Acre, Rondônia, Pará e Mato Grosso foram as regiões mais afetadas pelo desmatamento e pelas queimadas (DEON, 2013). Até 1980 o desmatamento na Amazônia correspondia a $300 \mathrm{mil} \mathrm{km}^{2}$, na década de 1990 cerca de 280 mil km² foram incorporados à esta área e em 2000 a área desmatada já totalizava 732 mil km², o equivalente a quase 15\% da Amazônia (BRASIL, 2008). O desmatamento seguido de queimadas, a atividade pecuária, o revolvimento do solo para implantação da agricultura e a exploração de minério são as principais fontes emissoras de $\mathrm{CO}_{2}$ e metano na Amazonia (FEARNSIDE, 2009; CARVALHO et al., 2010).

As queimadas que ocorrem após o desmatamento promovem a emissão de gases à atmosfera, não só da biomassa queimada más também da parte que não sofreu combustão. $O$ processo de queima libera gás carbônico $\left(\mathrm{CO}_{2}\right)$ e gases traços, como: metano $\left(\mathrm{CH}_{4}\right)$, monóxido de carbono $(\mathrm{CO})$ e oxido nitroso $\left(\mathrm{N}_{2}\right)$. Já a parte da biomassa que não é queimada será oxidada através da decomposição, processo onde ocorre a emissão de gás metano (FEARNSIDE, 2002).

O processo de ocupação do estado de Rondônia iniciou em 1877 com o primeiro ciclo da borracha. O mercado de látex estava em alta, e o governo brasileiro estimulou trabalhadores de todo o país a migrarem para a região norte, e ampliarem o extrativismo da Amazônia (ALBUQUERQUE, 2010; DIAS, 2015). O município de Porto Velho está situado à margem direita do rio Madeira ao Norte do estado de Rondônia e consiste na principal via de acesso entre Manaus (AM), Rio Branco (AC) e o centro-sul do Brasil. Surgiu por volta de 1907 com a construção da Estrada de Ferro Madeira Mamoré, e iniciou seu processo de colonização 
em 1970 estimulado por programas de incentivos fiscais do Governo Federal com migrantes das regiões Sul, Sudeste e Nordeste do Brasil (SILVA, 2010). A figura 1 apresenta o mapa de localização do município de Porto Velho.

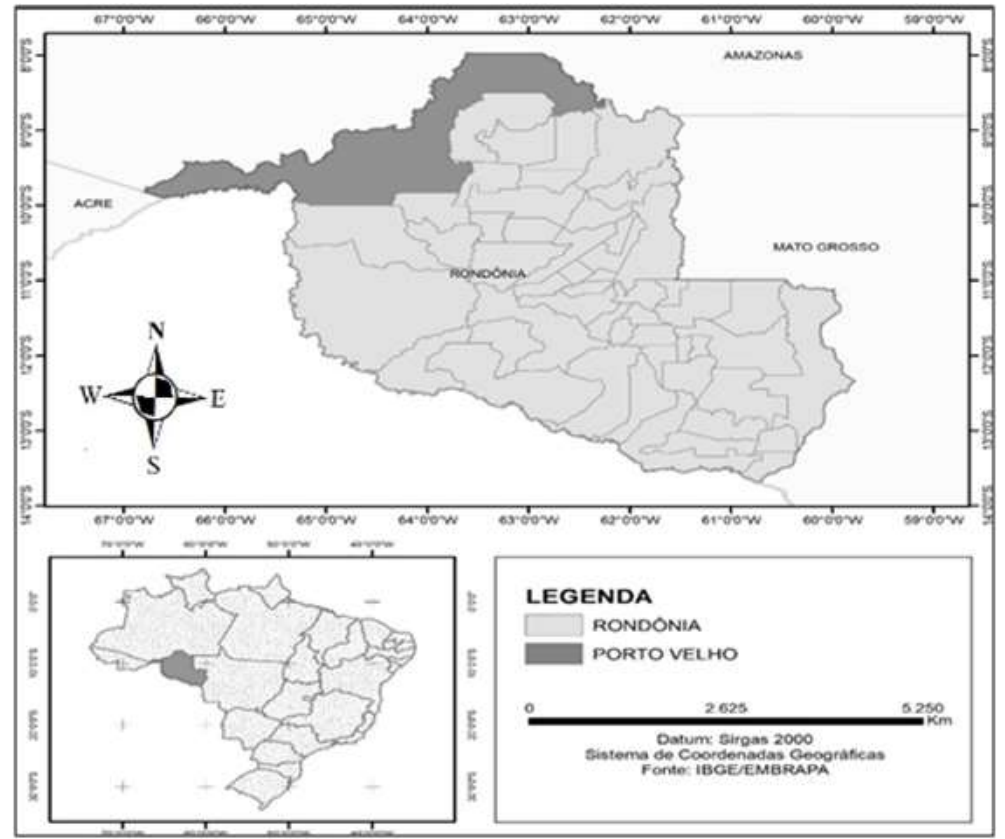

Figura 1: Mapa de localização do Município de Porto Velho. Fonte: Adaptação de IBGE (2014).

Porto Velho teve participação direta durante o regime de colonização do estado, sendo muitas vezes cenário dos projetos de assentamento do governo federal e de exploração de minério. Até os dias de hoje a agricultura e pecuária continuam sendo importantes matrizes econômicas do município, que juntamente com atividades industriais representam cerca de 40\% do PIB total (IBGE, 2014). Dados do último relatório de zoneamento do estado de Rondônia e registros realizados pelo Instituto Nacional de Pesquisas Espaciais (INPE, 2016) apontam que os índices de desmatamento continuam críticos para Porto Velho e região, com taxas de 26,5\% em 2015. Em 2008, Porto Velho foi inserido no Programa de Aceleramento do Crescimento (PAC) que estabeleceu a construção de duas usinas hidrelétricas no município, são elas Santo Antônio e Jirau.

Toda essa pressão sobre os recursos naturais de Porto Velho, nas mais diversas formas de exploração, como: extração de madeira, expansão agrícola e pecuária, construção de hidrelétricas e exploração mineral despertam hoje grande preocupação com relação aos possíveis efeitos no comportamento climático recorrentes deste processo. Deste modo, buscou-se com este estudo analisar indicadores ambientais, econômicos e sociais do município de Porto Velho no período de 1990 e 2015, além de verificar o comportamento do clima ao longo da série estudada, através das variáveis meteorológicas: temperatura, umidade relativa e precipitação.

\section{MATERIAIS E MÉTODOS}

A construção dos indicadores baseou-se na revisão bibliográfica acerca dos impactos sociais e ambientais decorrentes de atividades econômicas que fomentam grandes movimentos populacionais e uso intensivo dos recursos naturais, bem como, seus efeitos no sistema climático. No total, foram selecionados 25 indicadores que caracterizassem a dinâmica socioeconômica e ambiental de Porto Velho, para 
posteriormente eles serem enquadrados na abordagem Pressão - Estado - Resposta (PER). A série histórica analisada neste estudo compreendeu o período entre 1990 a 2015.

Para enquadrar os indicadores na abordagem PER, eles foram classificados em dimensão socioeconômica, dimensão da mudança de uso do solo e dimensão climática. Representando os indicadores de pressão foram elaborados indicadores relacionados às características populacionais, econômicas e de uso do solo de Porto Velho que tivessem coerência de causa e efeito com os indicadores de estado. Os indicadores de estado do meio ambiente são os que melhor refletem a informação de potencial alteração do meio ambiente e qualidade de vida da população, e os indicadores de resposta neste estudo se referem a dimensão climática, através das variáveis precipitação, temperatura e umidade relativa, de Porto Velho entre os anos 1990 e 2015. A tabela 1 apresenta os indicadores de dimensão socioeconômica, dimensão de mudança de uso do solo e dimensão climática enquadrados na classificação de Pressão - Estado - Resposta (PER).

Tabela 1: indicadores de dimensão socioeconômica, dimensão de mudança de uso do solo e dimensão climática enquadrados na classificação de Pressão - Estado - Resposta para Porto Velho.

\begin{tabular}{|c|c|c|}
\hline \multirow[b]{3}{*}{ 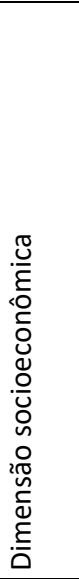 } & & Indicadores \\
\hline & Pressão & $\begin{array}{l}\text { Crescimento demográfico (no indivíduos/ano) } \\
\text { Produto Interno Bruto (PIB) (R\$/ano) } \\
\text { Frota de veículos automotores por mil habitantes (no veículos/ano), } \\
\text { Produção de energia (MW/hora) }\end{array}$ \\
\hline & Estado & $\begin{array}{l}\text { Índice de Gini (0-1) } \\
\text { População } \geq 18 \text { anos com ensino fundamental completo (\%/ano) } \\
\text { Esperança de vida ao nascer (\%/ano) } \\
\text { População economicamente ativa ocupada(\%/ano) } \\
\text { População economicamente ativa desocupada(\%/ano) } \\
\text { Renda per capita (\$/ano) } \\
\text { Taxa de analfabetismo (\%/ano) } \\
\text { № de matrículas (no alunos/ano) } \\
\text { Pessoas abaixo do nível de pobreza (no indivíduos/ano) } \\
\text { Emissão de CO2e (T/ano) }\end{array}$ \\
\hline \multirow{2}{*}{ 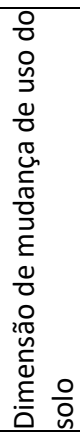 } & Pressão & $\begin{array}{l}\text { Área plantada de grãos e cereais(ha/ano) } \\
\text { Área plantada de frutas (ha/ano) } \\
\text { Área plantada de caules, raízes e gramíneas (ha/ano) } \\
\left.\text { Área de reservatório das hidrelétricas ( } \mathrm{km}^{2} / \mathrm{ano}\right) \\
\left.\text { Extração de madeira ( } \mathrm{m}^{3} / \mathrm{ano}\right) \\
\text { Efetivo bovino ( } \mathrm{n} \text { o cabeças/ano) }\end{array}$ \\
\hline & Estado & $\begin{array}{l}\left.\text { Área de cobertura florestal ( } \mathrm{km}^{2} / \mathrm{ano}\right) \\
\text { Área desmatada ( } \mathrm{km}^{2} / \mathrm{ano} \text { ) } \\
\text { Emissão de CO2e (T/ano) } \\
\text { Focos de queimadas km/ano } \\
\text { Área queimada /ano }\end{array}$ \\
\hline 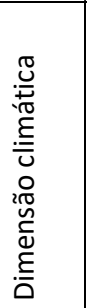 & Resposta & $\begin{array}{l}\text { Redução ou aumento de } \mathrm{CO}_{2} \text { (T/ano) } \\
\text { Temperatura }(\stackrel{\mathrm{o}}{ }) \\
\text { Umidade relativa (\%) } \\
\text { Precipitação (mm) } \\
\text { Implementação de medidas de comando e controle governamentais e/ou voluntarias do setor privado } \\
\text { relativas as pressões e ao estado; } \\
\text { Implementação de medidas jurídicas (leis, portarias, resoluções nacionais e internacionais que beneficiaram } \\
\text { o comando e controle). }\end{array}$ \\
\hline
\end{tabular}

Área plantada de grãos e cereais: arroz, soja, milho, café, feijão.

Área plantada de frutas: banana, melancia, mamão, laranja, maracujá, cacau, goiaba, tomate, limão.

Área plantada de caules, raízes e gramíneas: palmito, mandioca, cana-de-açúcar.

População economicamente ativa ocupada: percentual da população, com 18 anos ou mais, economicamente ativa ocupada.

População economicamente ativa desocupada: percentual da população, com 18 anos ou mais, economicamente ativa desocupada. 
Devido à ausência de série histórica referente a emissão de $\mathrm{CO}_{2}$ para o Município de Porto Velho, foi criado um fator de alocação município/estado. Com o fator de alocação foi possível estimar as emissões anuais de $\mathrm{CO}_{2}$ em Porto Velho tomando como referência a proporção de 27,43\% das emissões de Rondônia. Quanto às análises estatísticas deste estudo, inicialmente foi utilizado o modelo linear generalizado, tendo como variáveis explicativas: crescimento demográfico, PIB, área de floresta e área desmatada. Para esta análise foram considerados somente os indicadores com disponibilidade de dados entre os anos 2000 e 2015. Posteriormente, através do critério de Akaike verificou quais indicadores estariam associados ao aumento dos níveis de gases de $\mathrm{CO}_{2}$. $\mathrm{Na}$ análise dos indicadores da dimensão climática a variável emissão de $\mathrm{CO}_{2}$ foi utilizada como explicativa para temperatura, umidade relativa e precipitação. Todas as análises estatísticas foram realizadas no software "R" versão 3.3.2 (R DEVELOPMENT CORE TEAM, 2015).

\section{RESULTADOS}

A tabela 2 apresenta os indicadores socioeconômicos de Porto Velho para os anos 1990, 2000 e 2010.

Tabela 2: Indicadores socioeconômicos de Porto Velho para os anos 1990, 2000 e 2010.

\begin{tabular}{|c|c|c|c|}
\hline & 1990 & 2000 & 2010 \\
\hline Renda per capita (\$/no habitantes) & 486,00 & 613,00 & 929,19 \\
\hline Taxa de analfabetismo (\%/no habitantes) & 16,8 & 11 & 6,6 \\
\hline População $\geq 18$ anos com ensino fundamental completo(\%/ano) & 32,28 & 49,11 & 61,88 \\
\hline Esperança de vida ao nascer (\%/ano) & 62,99 & 67,22 & 74,14 \\
\hline Pessoas abaixo da linha de pobreza (\%/no habitantes) & 8,4 & 7,81 & 2,64 \\
\hline Pop. Economicamente ativa ocupada (\%/no habitantes) & - & 72,32 & 70,84 \\
\hline Pop. Economicamente ativa desocupada (\%/no habitantes) & - & 15.34 & 5.61 \\
\hline Índice de Gini (0-1) & 0,58 & 0,61 & 0,57 \\
\hline
\end{tabular}

O indicador renda per capita apresentou taxa de crescimento de 91,02\% entre os anos 1990 e 2010. A taxa média anual de crescimento foi de 2,61\%, entre 1991 e 2000, e 4,24\%, entre 2000 e 2010 . Em relação a proporção de pessoas abaixo da linha de pobreza, a taxa reduziu de8,40\%, em 1990, para 7,81\%, em 2000, e para 2,64\%, em 2010. A esperança de vida ao nascer cresceu 6,9 anos na última década, passando de 63,0 anos em 1990 para 67,2 anos em 2000, e 74,1 anos em 2010.

Entre 2000 e 2010o percentual de atividade da população economicamente ativa ocupada passou de 72,32\% em 2000 para 70,84\% em 2010. Ao mesmo tempo, o percentual de atividade da população economicamente ativa desocupada passou de 15,34\% em 2000 para 5,61\% em 2010. A taxa de analfabetismo reduziu de 16,8\% em 1990 para $11 \%$ em 2000 e 6,6\% em 2010. Ao mesmo tempo o percentual correspondente a população com 18 anos ou mais com ensino fundamental completo aumentou de $32,28 \%$ em 1990 para 49,11\% em 2000 e 61,88\% em 2015. A desigualdade de renda da população apresentou crescimento entre 1990 e 2000. O índice de Gini em 1990 correspondia a 0,58, no ano de 2000 esse valor estava em 0,61 e em 2010 0,57. Na tabela 3 estão apresentados os indicadores de mudança de uso do solo de Porto Velho para os anos 2005, 2010 e 2015.

O indicador área de cobertura florestal apresentou taxa de redução de 12\% entre os anos 2005 e 2015. A taxa média anual de decréscimo foi de 0,9\%, entre 2005 e 2010, e 1,57\%, entre 2010 e 2015. Em 
relação a área plantada houve um aumento de 20.562 ha em 2015 comparado a 2005. A extração de madeira cresceu $257.528 \mathrm{~m}^{3}$ na última década, passando de $314.784 \mathrm{~m}^{3}$ em 2005 para $572.312 \mathrm{~m}^{3}$ em 2015.

Tabela 3: Indicadores de mudança de uso do solo de Porto Velho para os anos 2000, 2005, 2010 e 2015.

\begin{tabular}{|l|l|l|l|}
\hline & 2005 & 2010 & 2015 \\
\hline Área de cobertura florestal (km²/ano) & 26.879 & 25.574 & 23.631 \\
\hline Área plantada (ha/ano) & 8.047 & 7.139 & 28.609 \\
\hline Área de reservatório das hidrelétricas (km²/ano) & - & - & 783,2 \\
\hline Extração de madeira (m/ano) & 314.784 & 444.379 & 572.312 \\
\hline Efetivo bovino (no cabeças/ano) & 597.067 & 609.860 & 834.570 \\
\hline
\end{tabular}

Em relação aos indicadores de mudança de uso do solo, o indicador efetivo bovino foi o que apresentou valores de crescimento mais significativos. Em 2005 o número de cabeças bovinas em Porto Velho era de 597.067, passando para 609.860 em 2010 e 834.570 em 2015. Isso representa um crescimento de 40\%de 2005 para 2015. Segundo o critério de Akaike, os indicadores crescimento demográfico, PIB e área desmatada foram os que melhor explicaram a variação das emissões de $\mathrm{CO}_{2}$. A figura 2 apresenta as taxas de emissões de $\mathrm{CO}_{2}$ para o município de Porto Velho para o período de 1990 e 2015.

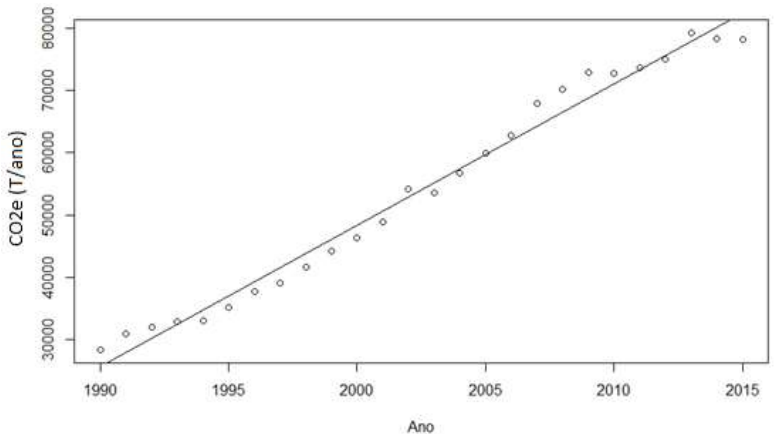

Figura 2:Taxa de Emissão de $\mathrm{CO}_{2}$ (t/ano) para o município de Porto Velho para o período de 1990 a 2015. Fonte: SEEG (2016).

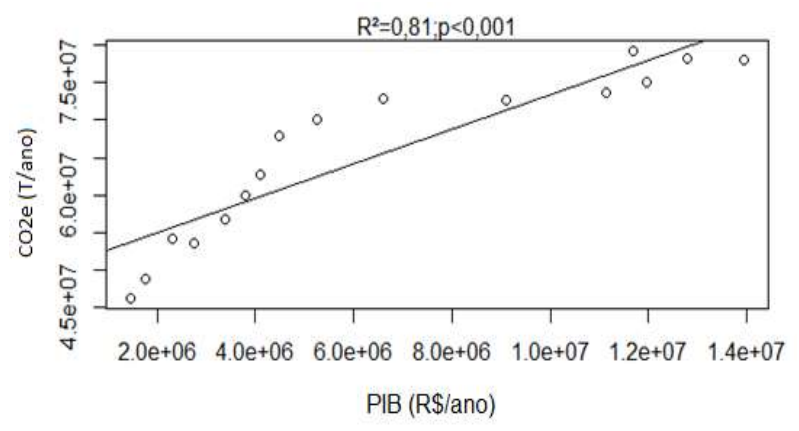

Figura 3: Emissões anuais de $\mathrm{CO}_{2}$ e o crescimento do PIB de Porto Velho entre os anos 2000 e 2015.

A taxa de emissão de $\mathrm{CO}_{2}$ apresentou taxa de crescimento anual de 4,13\% entre o período analisado, aumentado de 28.350.825t em 1990 para 78.144.504t em 2015. A figura 3 apresenta a taxa de emissão de $\mathrm{CO}_{2}$ e o crescimento do PIB de Porto Velho entre os anos 2000 e 2015. O PIB de Porto Velho apresentou taxa de crescimento anual de 16,2\% entre o período analisado. Entre 2000 e 2015 o aumento total foi de $\mathrm{R} \$ 12.476 .890$. A figura 4 apresenta as emissões de $\mathrm{CO}_{2} \mathrm{e}$ o aumento da área desmatada de Porto Velho entre os anos 2000 e 2015.

As áreas desmatadas aumentaram em $5.259 \mathrm{~km}^{2}$, de 2000 a 2015. A taxa de crescimento anual foi correspondente a 5,8\%. A figura 5 apresenta as emissões de $\mathrm{CO}_{2} \mathrm{e}$ o crescimento demográfico de Porto Velho entre os anos 2000 e 2015. A população de Porto Velho aumentou na ordem de 176.741 habitantes de 2000 para 2015. A taxa anual de crescimento entre o período analisado foi de 2,3\% e 54,2\% entre 2000 e 2015 . 




Figura 4: Emissões anuais de $\mathrm{CO}_{2}$ e o aumento da área desmatada de Porto Velho entre os anos 2000 e 2015.

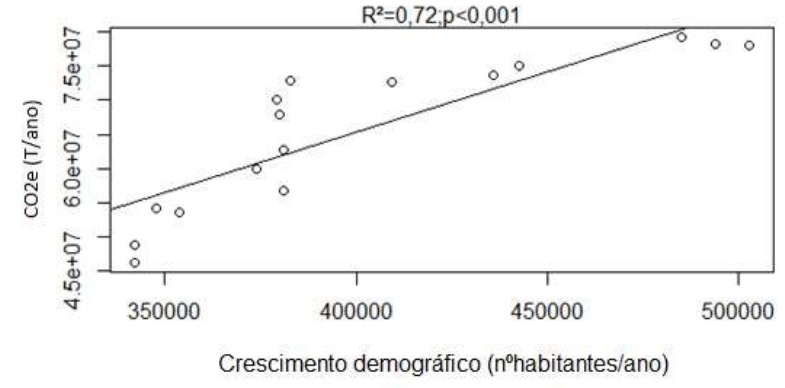

Figura 5:Emissões anuais de $\mathrm{CO}_{2}$ e o crescimento demográfico de Porto Velho entre os anos 2000 e 2015.

\section{Indicadores de resposta}

$\mathrm{Na}$ análise dos indicadores da dimensão climática a variável $\mathrm{CO}_{2}$ foi utilizada como explicativa para as variações de temperatura, umidade relativa e precipitação. A figura 6 apresenta a temperatura média anual de Porto Velho entre os anos 1990 e 2015.

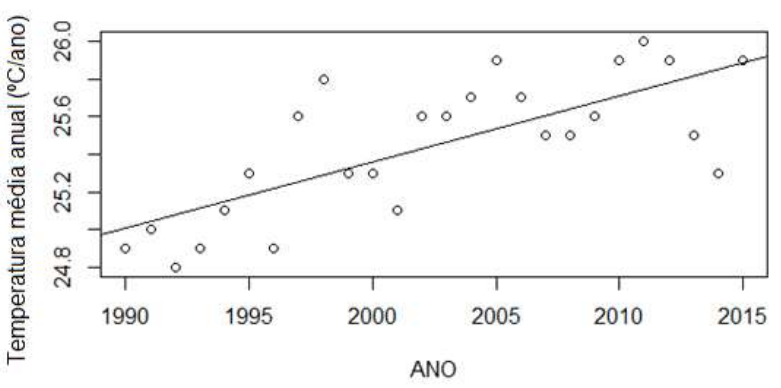

Figura 6: Temperatura média anual de Porto Velho entre 1990 e 2015 (INMET, 2015).

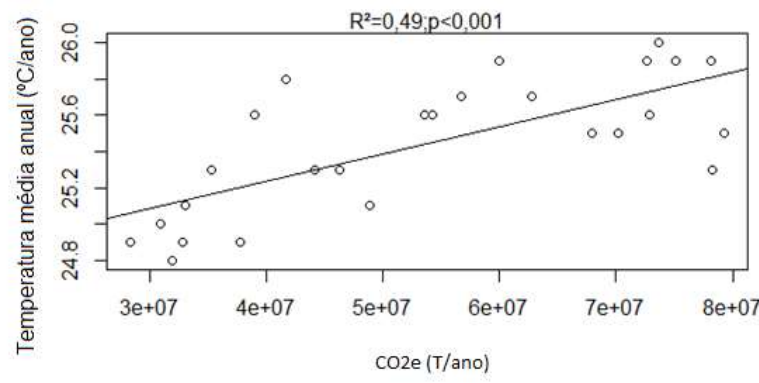

Figura 7: Emissões anuais de $\mathrm{CO} 2$ e a temperatura média anual de Porto Velho entre os anos 2000 e 2015.

A figura 6 evidencia a mudança do perfil de temperatura da década de 1990 para a década de 2000.0 indicador climático temperatura média anual apresentou taxa de crescimento equivalente a $4 \%$ entre 1990 e 2015. Aumentando de $24,9^{\circ} \mathrm{C}$ em 1990 para $25,9^{\circ} \mathrm{C}$ em 2015, ou seja, um aumento médio de $1^{\circ} \mathrm{C}$. Segundo o critério de Akaike, a variável temperatura foi a que apresentou maior associação com o indicador de taxa de emissão de $\mathrm{CO}_{2}$. O coeficiente de determinação $\left(\mathrm{R}^{2}\right)$ da análise foi 0,49. A figura 7 apresenta as taxas de emissões de $\mathrm{CO}_{2}$ e a temperatura média anual de Porto Velho entre os anos 1990 e 2015. A figura 8 apresenta a Umidade Relativa (UR) média anual de Porto Velho entre e 1990 e 2015.

Para a variável meteorológica umidade relativa, a variabilidade interanual mostrou que entre os anos 1990 e 2015 ocorreu uma tendência negativa da UR média do ar na ordem de -0,22\% por ano. Este resultado corresponde a um decréscimo de 5,4\% no ano de 2015 comparado a 1990. A redução da umidade relativa induz maior inflamabilidade de áreas de floresta. A figura 9 apresenta as taxas de emissões de $\mathrm{CO}_{2}$ e a umidade relativa média anual de Porto Velho entre os anos 1990 e 2015.

A figura 10 apresenta a precipitação média anual de Porto Velho entre e 1990 e 2015 . Ao observar os dados referentes a precipitação média anual de Porto Velho, constata-se um aumento de 409,6 mm entre a série analisada. Em 1990 a média anual foi 2.352,9mm e em 2015 este valor aumentou para 2.762,5mm, o que equivale a um aumento de $0,64 \%$ ao ano. A figura 11 apresenta a precipitação média anual e as emissões de $\mathrm{CO}_{2}$ de Porto Velho entre os anos 1990 e 2015. 


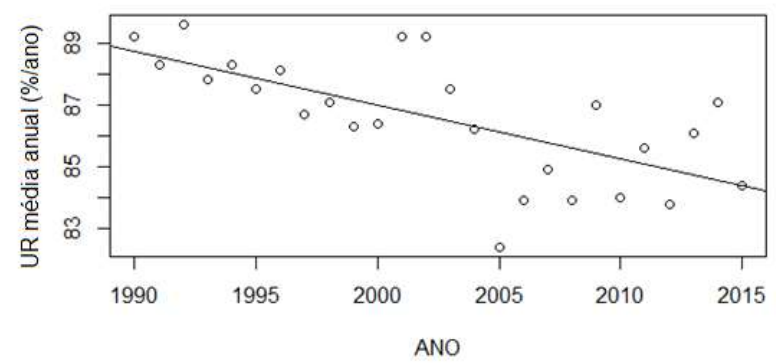

Figura 8: Umidade Relativa média anual de Porto Velho entre e 1990 e 2015 (INMET, 2015).

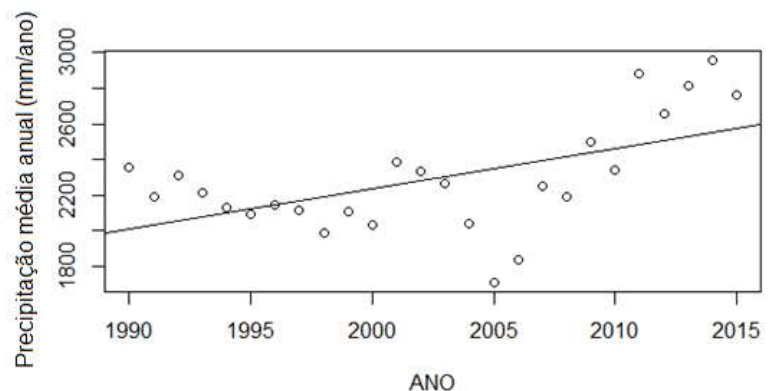

Figura 6: Precipitação média anual de Porto Velho entre e 1990 e 2015 (INMET, 2015).

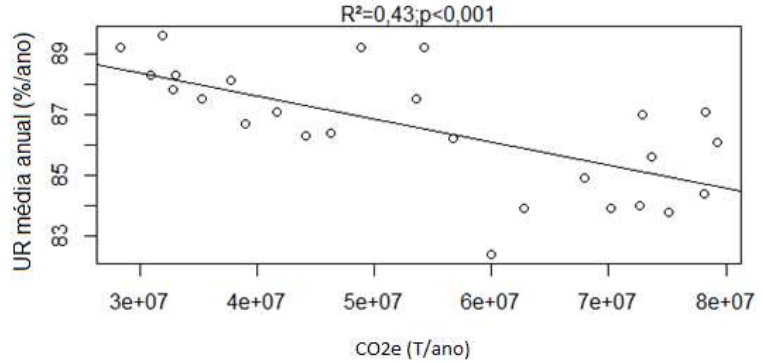

Figura 9: Umidade relativa média anual e emissões de CO2 de Porto Velho entre os anos 1990 e 2015.

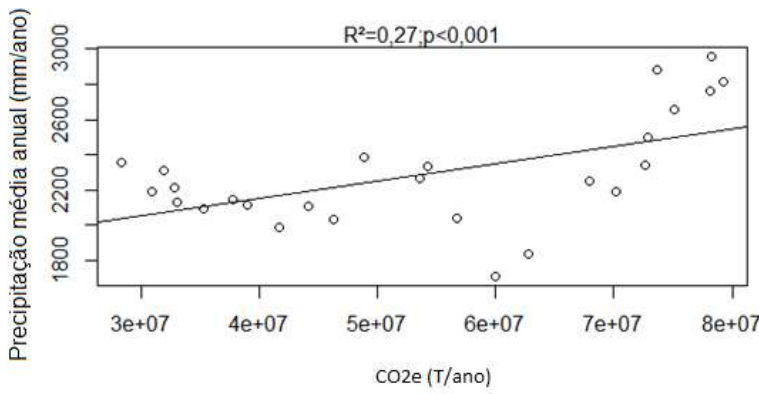

Figura 11: Precipitação média anual e emissões de CO2 de Porto Velho entre os anos 1990 e 2015.

\section{DISCUSSÃO}

Dado o enquadramento dos indicadores de pressão e estado nas dimensões socioeconômicas e mudança de uso do solo para Porto Velho entre os anos 1990 e 2015, foi possível realizar uma análise sobre o atual cenário do município, bem como o comportamento da variabilidade climática frente as principais mudanças socioeconômicas e ambientais.

Observou-se através dos dados referente aos indicadores: crescimento demográfico, PIB, renda per capita e frota, que a medida que a população do município de Porto Velho foi aumentando, a economia foi se fortalecendo e a quantidade de veículos automotores cresceram, as concentrações de $\mathrm{CO}_{2}$ no sistema climático apresentaram um incremento gradativo. Este resultado corrobora com estudos anteriores de Cerri et al. (2007) e Rocha et al. (2014), que atribuem o aumento das emissões deCO ${ }_{2}$ à queima de combustíveis fósseis e incremento da economia.

O indicador número de matriculas, que representa o número de pessoas matriculadas em ensino fundamental, médio e superior por ano em Porto Velho apresentam um decréscimo de 9,3\% entre os anos 2005 e 2015. O indicador taxa de analfabetismo apresentou bons resultados se comparado entre 1990 e 2010, com um incremento de melhoria de $16,8 \%$ para $6,6 \%$, já o indicador renda per capita praticamente dobrou entre estes mesmos anos, aumentando de $\mathrm{R} \$ 486,00$ para $\$ 929,19$. A taxa de população abaixo da linha de pobreza também apresentou bons resultados, com decréscimo de 5,8\% no ano de 2010 comparado a 1990. Curiosamente os dados referentes ao índice de Gini não apresentaram resultados positivos, pois em 1990 eles correspondiam à 0,58 e em 2010 a 0,57.

Em relação a dimensão mudança de uso do solo, os dados referente ao indicador efetivo bovino também apresentou crescimento entre 2000 e 2015. Estes resultados fortalecem estudos que atribuem o 
aumento das emissões de $\mathrm{CO}_{2}$ à mudança de uso do solo (CERRI et al., 2007; CARVALHO et al., 2010; IPCC, 2014) e fermentação entérica, através da pecuária (MOMBACH et al., 2016; SEEG, 2016).

O desmatamento é uma das práticas mais preocupantes nos estados que compõem o bioma Amazônia, principalmente quando seguida de queimadas. No entanto como as matrizes econômicas desta região demandam grandes extensões territoriais, seja para a pecuária, agricultura, extração vegetal ou extração mineral, esta questão tem preocupado cada vez mais a comunidade científica. Há algumas políticas que criminalizam a extração de madeira sem manejo florestal, a exploração de ouro no Rio Madeira, a prática de queimadas dentre outras atividades que acarretam danos ambientais. Mesmo assim, é possível observar que quando se trata de crescimento econômico a legislação se apresenta flexível.

Além das pressões decorrentes da mudança de uso do solo, Fearnside enfatiza as pressões decorrentes das usinas hidrelétricas e termelétricas, principais fontes geradoras de energia elétrica do Brasil, e frequentemente presente na Amazônia. Nas usinas termelétricas ocorre a queima de combustíveis fósseis como gás natural, óleo e carvão, resultando na emissão de $\mathrm{CO}_{2}$ na atmosfera. No entanto, estudos apontam que as hidrelétricas, que já foram consideradas como uma fonte de energia limpa, podem ser tão poluentes quanto as usinas termelétricas (BERMANN et al., 2010; GREENPEACE, 2016). Isso se dá pelo fato que, para a construção de hidrelétricas é obrigatório a retirada da vegetação nas áreas de reservatório que serão inundadas, no entanto a decomposição da matéria orgânica que sobra do corte das árvores e do carbono presente no solo acarretam a formação de gás carbônico e metano que são posteriormente liberados na atmosfera. Acontece que o metano é 32 vezes mais potente no efeito estufa do que o gás carbônico, por este motivo o impacto das hidrelétricas vem sendo equiparado ou superior as termelétricas que emitem $\mathrm{CO}_{2}$ (GREENPEACE, 2016).

Massoli et al. (2014) utilizaram a metodologia PER para analisar as principais externalidades que foram potencialmente geradas pela Usina Hidrelétrica - UHE construída no município de Estreito (Maranhão) a partir de impactos econômicos, sociais e ambientais. As principais externalidades pontuadas pelos autores foram: ausência de desenvolvimento para a cidade em âmbito social, avaliação subestimada das terras dos moradores que residiam no local onde foi construída a usina, morte e deslocamento da fauna, elevação no custo de vida e aumento da criminalidade. No caso de Porto Velho também é possível identificar estas mesmas externalidades para a população local ao analisar os indicadores socioeconômicos de pressão e estado. Em síntese, conclui-se a respeito das construções da Usinas Hidrelétricas Santo Antônio e Jirau, que as outras regiões do Brasil que recebem energia para consumo residencial e industrial estão em melhores condições de vida, pois além de se beneficiarem com a energia não são afetadas pelos passivos ambientais.

Sobre os indicadores da dimensão climática se percebe que houve algumas variações entre os anos 1990 e 2015.Em relação ao indicador precipitação se constatou um aumento de 409,6 mm entre a série analisada, o que corresponde a um aumento de $0,64 \%$ ao ano. Esta variação de comportamento pode ser decorrente principalmente das atividades de desmatamento, pois ela interfere diretamente sobre o ciclo hidrológico. Estudos de Campos et al. (2009) apontam que a Floresta Amazônica desempenha papel fundamental no ciclo hidrológico local e regional devido ao seu potencial de evapotranspiração. Os 
pesquisadores ainda ressaltam que este bioma contribui não só para o ciclo hidrológico das regiões que o compõem, mas para todo o Brasil devido ao movimento dos ventos alísios. Quanto à variável meteorológica UR, que diz respeito à umidade do ar, entre 1990 e 2015, percebe-se que a medida que as emissões de $\mathrm{CO}_{2}$ foram aumentando a umidade do ar foi reduzindo. Já em relação à variável temperatura, a correlação com o indicador $\mathrm{CO}_{2}$ foi positiva ao nível de 49\%. Este resultado corrobora com diversas pesquisas que apontam o aumento das concentrações de $\mathrm{CO}_{2}$ como o principal causador do aumento da temperatura do planeta (IPCC, 2007).

Quanto as emissões de $\mathrm{CO}_{2}$ em Porto Velho do ano 1990 para 2015 houve um aumento de 49.793 .679 (milhões) de toneladas. Ao analisar as emissões de $\mathrm{CO}_{2}$ em escala interanual percebe-se claramente uma tendência crescente das emissões para o município de Porto Velho. Em 1990 as emissões totais de $\mathrm{CO}_{2}$ registradas foram de 28.350,83t e em 2015 estavam em 78.144,50t, ou seja, houve um aumento de 49.793.679t entre os respectivos anos, sendo o aumento anual equivalente a4,13\%. Os dados apresentados pela plataforma SEEG engloba as emissões dos seguintes setores: agropecuária, energia, mudança de uso da terra, processos industriais e resíduos (SEEG, 2017).

\section{CONCLUSÕES}

Ao fim deste estudo conclui-se que o município de Porto Velho/Rondônia entre os anos 1990 a 2015 passou por diversas alterações no que se refere a dinâmica de uso dos ecossistemas naturais, urbanização e aumento das atividades econômicas. Observa-se um aumento na variável meteorológica temperatura de 1ํC em 2015 se comparado ao ano 1990 e um decréscimo na variável umidade relativa de 5,4\% nos respectivos anos. É precipitado afirmar que esta alteração no clima seja decorrente da dinâmica de uso do solo e urbanização desenvolvida em Porto Velho, no entanto as análises estatísticas mostraram fortes correlações entre os indicadores de uso do solo com emissão de $\mathrm{CO}_{2}$.

Outra questão importante observada com a pesquisa é em relação a qualidade de vida da população que reside em Porto Velho. Durante o período estudado foi observado um incremento significativo em relação à economia do município, principalmente após a implantação das usinas hidrelétricas Santo Antônio e Jirau no Rio Madeira. Entretanto, esta evolução dos indicadores econômicos não foi proporcionalmente observada em indicadores sociais, ou seja, a população de Porto Velho vem sofrendo com as externalidades ambientais decorrentes do crescimento econômico, porém não compartilham dos benefícios que os mesmos podem gerar.

\section{REFERÊNCIAS}

ALbuQUerque, M. J. N.. Estrada do Pacífico: influência de sua implantação no espaço circulante no trecho de Brasiléia à Assis Brasil/Acre. Dissertação (Mestrado em Geografia) Fundação Universidade Federal de Rondônia, Porto Velho, 2010.

BERMANN, C.; WITTMANN, D.; HERNANDEZ, F. D. M.; RODRIGUES, L. A.. Usina Hidrelétrica na Amazônia: O futuro sob as águas. In: SEMINÁRIO DE POLÍTICAS PÚBLICAS E
OBRAS DE INFRA-ESTRUTURA NA AMAZÔNIA: CENÁRIOS E DESAFIOS PARA O FORTALECIMENTO DA GOVERNANÇA SOCIOAMBIENTAL. Anais. Brasília, 2010.

BRASIL. Sistema Nacional de Informações Florestais. Pressão e Impacto sobre as florestas. Brasília: SNIF, 2008.

CAMPOS, M. T.; HIGUCHI, F. G.. A Floresta Amazônica e seu Papel nas Mudanças Climáticas. Manaus, 2009. 
CARVALHO, J. L. N.; AVANZI, J. C.; SILVA, M. L. N.; MELLO, C. R.; CERRI, C. E. P.. Potencial de Sequestro de Carbono em Diferentes Biomas do Brasil. Revista Brasileira de Ciência do Solo, v.34, n.2, p.277-290, 2010.

CERRI, C. C.; CERRI, C. E.. Agricultura e aquecimento global. Boletim da Sociedade, v.32, n.19, p.40-44, 2007.

CERRI, C. C.; MAIA, S. M. F.; GALDOS, M. V.; CERRI, C. E. P.; FEIGL, B. J.; BERNOUX, M.. Brazilian Green house Gas Emissions: The importance of agriculture and lives tock. Sci. Agric., Piracicaba, v.66, n.6, p. 831-843, 2009.

DEON, D. S.. Mudança de uso da terra e impacto na matéria orgânica do solo em dois locais no Leste da Amazônia. Tese (Doutorado) - Escola Superior de Agricultura Luiz de Queiroz, Piracicaba, 2013.

DIAS, R. H. S.. Análise do Uso e Ocupação do Solo e do Comportamento da Bacia Hidrográfica do Rio Machado em Eventos Hidrológicos Extremos. Dissertação (Mestrado em Geografia) - Fundação Universidade Federal de Rondônia, Porto Velho, 2015.

FEARNSIDE, P. M.. Fogo e emissão de gases de efeito estufa dos ecossistemas florestais da Amazônia brasileira. Estudos Avançados, São Paulo, v.16, n.44, p.99-123, 2002.

FEARNSIDE, P. M.. Global warming in Amazonia: impacts and mitigation. Acta Amazônica, v.39, n.4, p.1003-1011, 2009.

GREENPEACE. Hidrelétricas na Amazônia: um mau negócio para o Brasil e para o mundo. São Paulo: GREENPEACE, 2016.

IBGE. Instituto Brasileiro de Geografia e Estatística. Produto Interno Bruto do Município de Porto Velho. 2014.

INPE. Instituto Nacional de Pesquisas Espaciais. Observação da Terra: Taxas anuais do desmatamento, 1988 até 2015. 2016.
IPCC. Intergovernmental Panel on Climate Change. Climate Change 2007: Impacts, Adaptation and Vulnerability. 2007.

IPCC. Intergovernmental Panel on Climate Change. Fifth Assessment Synthesis Report. 2014.

MASSOLI, E. C.; BORGES, F. Q.. Análise das externalidades geradas pela Usina Hidrelétrica de Estreito (MA) e o Processo de Desenvolvimento. Desenvolvimento em Questão, v.12, n.28, p.251-278, 2014. DOI: http://doi.org/10.21527/2237-6453.2014.28.251-278

MOMBACH, M. A.; PEDREIRA, B. C.; PEREIRA, D. H.; CABRAL, L. S.; RODRIGUES, R. A. R.. Emissão de Metano Entérico por Bovinos: o que sabemos e o que podemos fazer?. In: Recuperação de Pastagens. EMBRAPA, 2016.

PIFER, A.; AURANI, K. M.. The analytical theory of heat of Joseph Fourier: an analysis of the conceptual and epistemological foundations. Revista Brasileira Ensino Físico, v.37, n.1, 2015. DOI: http://dx.doi.org/10.1590/S1806-11173711681

ROCHA, B. N.; BRANCO, K. S.; PEREIRA, L.; BRANCO, M. C. Caderno: Mudança Global do Clima. O que está acontecendo com o planeta Terra. São Paulo, 2014.

SEEG. Sistema de Estimativa de Emissões de Gases de Efeito Estufa. Agropecuária. 2016

SILVA, F. A. M.. Hidrelétrica, Indústria e a Formação do Circuito Superior da Economia Urbana em Porto Velho. Dissertação (Mestrado em Geografia) - Fundação Universidade Federal de Rondônia, Porto Velho, 2010.

SOARES, L. M. P. M.. Alterações Climáticas: breve enquadramento histórico. Lisboa, 2014.

A CBPC - Companhia Brasileira de Produção Científica (CNPJ: 11.221.422/0001-03) detém os direitos materiais desta publicação. Os direitos referem-se à publicação do trabalho em qualquer parte do mundo, incluindo os direitos às renovações, expansões e disseminações da contribuição, bem como outros direitos subsidiários. Todos os trabalhos publicados eletronicamente poderão posteriormente ser publicados em coletâneas impressas sob coordenação da Sustenere Publishing, da Companhia Brasileira de Produção Científica e seus parceiros autorizados. Os (as) autores (as) preservam os direitos autorais, mas não têm permissão para a publicação da contribuição em outro meio, impresso ou digital, em português ou em tradução. 